\title{
Implementation of Total Quality Management in Higher Pharmaceutical Education: Opportunity and Challenge
}

\author{
Xiangling $\mathrm{Gu}^{1 *}$, Xinfeng Song ${ }^{1}$, Maojiang Dong ${ }^{1}$, Hanwen Sun ${ }^{1}$, Jing $\mathrm{Li}^{1}$, Guiyun $\mathrm{Liu}^{1}$, Jiwei Wu${ }^{1}$, \\ Fanfang $\mathrm{HaO}^{2}$ and Yong $\mathrm{Li}^{3}$
}

${ }^{1}$ College of Medicine and Nursing, Shandong provincial engineering laboratory of novel pharmaceutical excipients, sustained and controlled release preparations, Dezhou University, Dezhou, 253023, China.

${ }^{2}$ Radiology Department, Ningyang hospital of traditional Chinese medicine, Shandong, 271400, China.

${ }^{3}$ Pharmacy Department, Taian rongjun hospital, Taian, 271000, China.

\begin{abstract}
Introduction: Higher pharmaceutical education in China has made a great development in recent years. A few problems, such as unevenness of school-running level, lack of students innovation and deficiency of teaching effect, are also exposed in its rapid development. The reasons for these challenges are also revealed that old teaching mode and increasing enrollment scale in China's university may be the primary causes. Methods: To face these problems, some measures should be taken. Total quality management (TOM), as a novel teaching concept, is proposed in this article to integrate into higher pharmaceutical education in China. Results: To implement TOM, suggestions are given to emphasize on professional ethics, course quality and practice teaching. Firstly, the educators should take pharmacy moral as one of the important contents and infiltrate it in all teaching activities so as to realize the cultivation of professional ethics. In addition, in order to improve course quality, it is necessary to implement curriculum reform by broadening curriculum caliber, optimizing curriculum system and removing regional segmentation in professional courses. What's more, practice teaching should be actively adopted to combine itself with higher pharmaceutical education in China due to it being a discipline depending largely on the practice. Conclusion: It is necessary to boost the TQM step by step within a healthy system, which will play an important role in improving the quality of pharmaceutical education. Though implementation of TQM in higher pharmaceutical education faces various opportunity and challenge, the philosophy of TOM will be gradually accepted by more and more universities.
\end{abstract}

Key words: Higher pharmaceutical education, Innovative ability, Professional ethics, Total quality management.

\section{INTRODUCTION}

With the advent of the era of economic globalization and knowledge economy, higher education in China received a rapid development and entered a stage of internationalization and popularization. Under this background, higher pharmaceutical education has made great development, especially the number of university setting up pharmaceutical speciality increased rapidly, which was up to 703 by the end of 2012, including 371 undergraduate universities, 46 medical junior college, and 286 independently established higher vocational college, which increased by 54, 6 and 100 respectively when compared to those of 2008. Among these universities, there are not only medical universities, but also other ones, such as comprehensive university, polytechnic college, chemical engineering college, scientific college, as well as colleges of agriculture, forestry, commerce, etc. It shows that higher pharmaceutical education in China has grown to a certain scale. A few problems, however, are also exposed in its rapid development, as Wang and $\mathrm{Li}$ reported. ${ }^{1}$

The unevenness of school-running level resulted from the unbalanced development of higher pharmaceutical education in dif-
Submission Date : 17-04-2015 Accepted Date : :19-07-2015

DOI: $10.5530 / i j p e r .50 .1 .5$ Correspondence Address Dr. Xiangling $\mathrm{Gu}$ Shandong Provincial Engineering Laboratory of Novel Pharmaceutical excipients,

Sustained and Controlled

Release Preparations, Dezhou University, Dezhou, 253023,

China.

Email:13853449009@163.com

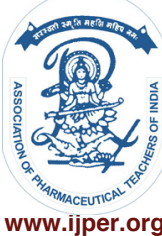




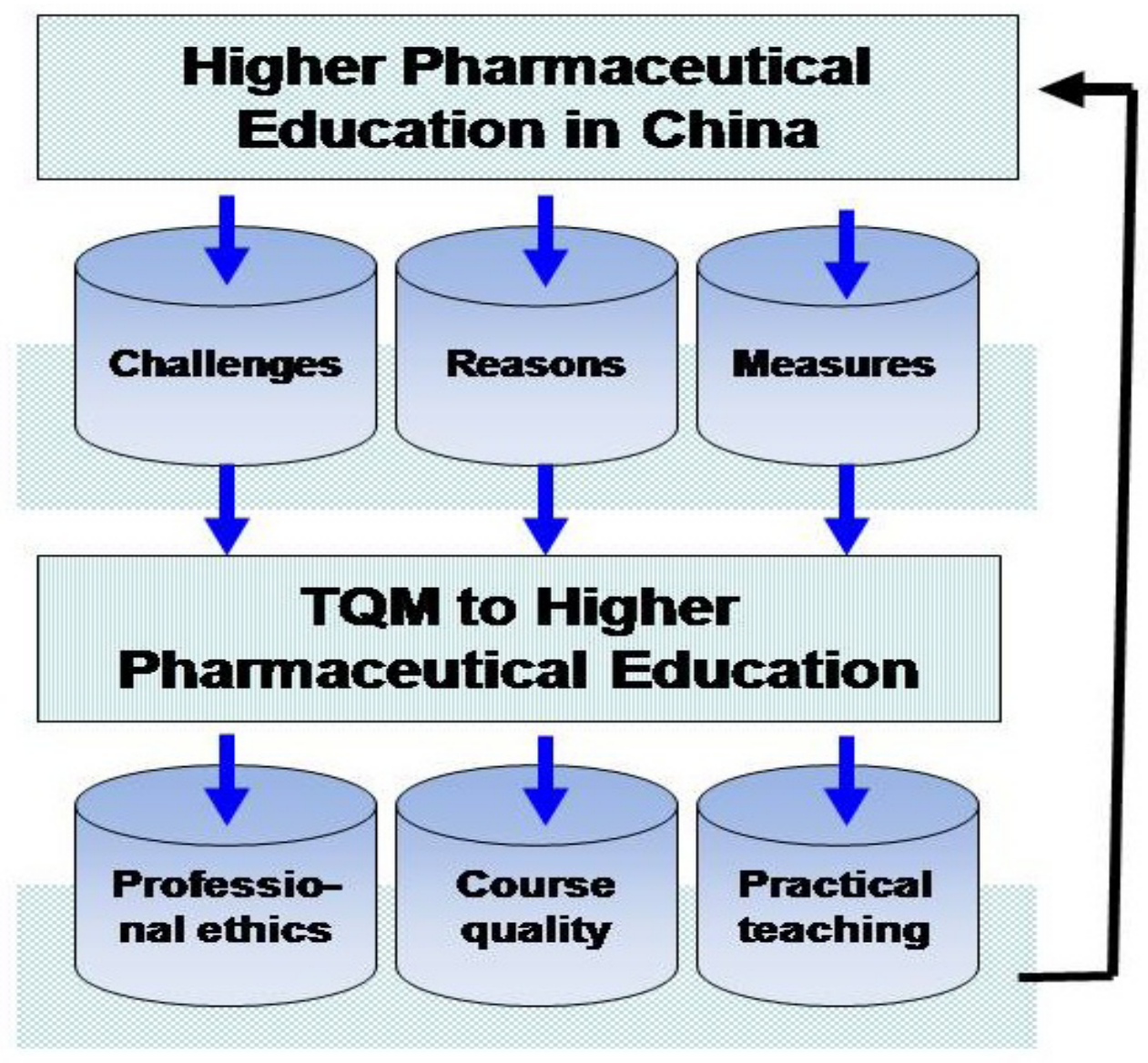

\section{Graphical Abstract}

ferent regions of China. The areas where pharmaceutical education was well developed mainly located in the coast regions of China and eastern or middle middle provinces because higher education therein has good foundation and their economy is well developed. The development of higher pharmaceutical education of western and remote areas, however, started lately and lagged behind by defective school-running condition and small scale of students recruitment, so that it is difficult to meet the requirements for pharmaceutical talents of medicine industry. ${ }^{1}$

Some universities have not yet fully settled themselves in the background of international higher education, that their teaching content, teaching means and teaching method are still belonging to the old mode. Consequently, the innovation ability and the comprehensive quality of the so-cultivated students fell far behind the international pharmaceutical students, which reduced the competitiveness of the graduates in the international and domestic employment market.

In recent years, the enrollment of pharmaceutical postgraduate increased sharply, therefore a large number of teachers, who have rich teaching experience and are of high scientific research level, need to undertake the heavy task of graduate cultivation, especially some teachers should guide even dozens of graduates, their time for teaching were seriously limited; On the other hand, the teaching effect was also influenced by the fact that many young teachers, despite of having high academic qualifications, lack of experience in teaching.

\section{METHODS}

Education quality is no doubt the lifeline of universities, so the most urgent need for the universities is how to improve the quality of education. In recent years, many scholars have introduced concept of the total quality management (TQM) into the research field of higher education, that some universities are also implementing TQM management to certain degree. ${ }^{2}$ TQM consists of organization-wide efforts to install and make permanent a climate in which an organization continuously improves its ability to deliver high-quality products and services to customers. While there is no widely agreedupon approach, TQM efforts typically draw heavily on the previously developed tools and techniques of quality control. TQM enjoyed widespread attention during the 
late 1980s and early 1990s. ${ }^{3,4}$ Higher pharmaceutical education has the features of quick updating of knowledge system, big investment of teaching instruments and high education cost. TOM is in the most economic level to fully meet social requirements under the present condition, which provides a new way to solve the problems of higher pharmaceutical education mentioned above. ${ }^{1,5,6}$ The following presented was five features of TQM closely related to the higher pharmaceutical education. ${ }^{1}$

\section{Comprehensiveness}

TQM emphasized on both the quality of teaching effect and the quality of education process. Taking teaching activity as the center, scientific research and logistics work were all subjected to a comprehensive management, for the sake of improving the quality of teaching with less quality loss and providing qualified talents to meet the requirement of society. ${ }^{7}$

\section{All-staff-participation}

TQM is of the management that needs all staffs participated. Both the teachers and the students were desiderated to care about the quality management of the university. ${ }^{8}$ Therefore, every department and every staff, should have quality awareness and make joint efforts for the development of the university.

\section{Whole-process-management}

TQM is one of the whole process managements, that is, each link of the process of education activity should be set under the control, to guarantee all the teaching activity carrying out step by step aiming at the school quality goals. ${ }^{910}$ Meanwhile, TQM requires system theory and method to build a strict quality system and emphasizes on the organic connection and cooperation among all the departments and all the links.

\section{Precaution}

It is necessary to adhere to the guideline of prevention first, quality control in advance and nip in the bud. It will take a long time to cultivate college students. ${ }^{11,12}$ After graduation, the post-test may find problems, but no help for the present talent cultivation. Although system management of no defect is only a kind of desired state, which need to conduct the student cultivation at each link without any fault, it is also a good way to control the quality of each step, thereby to improve the quality of personnel training.

\section{Continuity}

The purpose of implementing TQM is to achieve continuous quality improvement. ${ }^{13}$ Each staff is required to have mental preparation for continuous improvement, and genuinely realize the importance of continuous improvement for himself and the whole school. Different departments or primary-level organizations are required to build a series of complete plans in order to achieve continuous quality improvement with unity and cooperation. Once the continuous improvement of university activity becomes vigorous and effective, the continuous quality management throughout all the university is guaranteed.

\section{RESULTS}

The core of the implementing TQM is to carry out effective control on various factors and steps affecting education process, so as to ensure the educational quality, which involves all the activities in university, relates to all staffs of the university and goes through the whole education work..$^{14,15}$ Therefore, in order to construct TQM in higher pharmaceutical education, it is necessary to emphasize a kind of breakthrough thinking and insure the key tache of higher pharmaceutical education and its breakthrough point, upon considering each step of the education process.

\section{Professional ethics}

As is known that, China is a paradise of civilization for thousands of years. Ethic and virtue are both important contents of China's traditional culture. In the history of pharmacy development of China, the examples of prominent personages who were widely respected and admired are too numerous to be listed. The Chinese people praise highly the gracious moral sentiment since ancient times. But in recent years, a few practitioners ignore the medicine principle and violate the pharmaceutical ethics, whose behaviors seriously destroyed the normal order of drug circulation and severely damaged the credibility of the pharmaceutical industry. ${ }^{1}$

In the $21^{\text {st }}$ century, pharmaceutical workers are required not only higher professional knowledge and skills, but also noble professional ethics. Several years later, most students from medicine colleges will become the backbone of medicine enterprise in China, the level of their professional knowledge and moral qualities, will dominate the vicissitudes of the future medicine industry. The work to cultivate pharmaceutical students with healthy professional ethics, to help them form correct consciousness of professional moral and construct healthy professional ethics, is not only the need of the modern 
pharmaceutical enterprise, but also the fundamental guarantee to the culture of pharmaceutical industry.

Pharmaceutical colleges, therefore, should put the pharmaceutical moral education as an important content of promoting students' quality education, and infiltrate it in the teaching activity of professional theory course and other educational activities. Meanwhile, pharmaceutical education should be combined with the spirit of professional ethics, social morality and family virtue. In activities such as education activities for new students and the direction to graduate employment, students should be introduced to start consciously from themselves and from now on, to keep the idea in mind that patients should be admired as the center of all the activities. In addition, students should remember the pharmaceutical moral principle to heal the wounded and rescue the dying, and to provide safe, effective and economic drugs for the preventing and curing diseases with their whole hearts. Whether to protect the safety of patients should be taken as the evaluation criteria of students' value, and also, the safety and effectiveness of drugs should be taken as the basic ethical standards, in order to further improve the students pharmaceutical moral accomplishment.

\section{Course quality}

It is necessary to broaden the caliber of the curriculum to increase its adaptability. ${ }^{1,16}$ The basic courses are designed to include mathematics, physics, chemistry, computer, biosciences, medical knowledge, and some related curriculums, for example, production, inspection, distribution, management and security of medicines. By reasonable setting up of curriculum, it is beneficial for students not only to accept theories and skills, but also to enhance the ability to adapt to rapid development of pharmaceutical disciplines. In addition, overall optimization of the curriculum system is of particular importance. According to the general principles, one needs to adjust the course design at macro level and lead to a breakthrough in framework of secondary discipline by crossing multiple disciplines. Thirdly, it is also important to remove the malpractice of regional segmentation of professional courses, because they are mutually contacted and connected to each other. After the whole optimization, the integration of curriculum system is expected and will show the balance of structure, the mobility of setting up as well as the flexibility of development. The last but not the least is to increase the course of humanistic and social science. Most pharmaceutical colleges generally lack of the knowledge of aesthetics, anthropology, psychology, sociology, literature, and music, which is not conducive to achieve students' quality and accomplishment. Meanwhile, it needs to strengthen the spirit education of innovation, fighting as well as cooperation.

\section{Practice teaching}

Pharmacy is a discipline depending largely on the practical application, in which all theory, creation, validation, and research must rely on the practice, for example, research methods, scientific experiments, achievement transformation, production and management, etc. ${ }^{1}$ As a result, the practice teaching is of important position in higher pharmaceutical education, which plays a key role in achieving all-round developed pharmaceutical talents with creative consciousness and innovation ability, and is also a breakthrough point with unique function that can not be replaced by any other way. In such teaching activity, students can accept more rigorous scientific attitude besides learning some basic knowledge, methods and skills. The development of science and technology will inspire the exploration spirit and creation passion, which leads to formation of the ability of independent thinking and the ability to analyze and solve questions. Therefore, practice teaching should be actively combined with higher pharmaceutical education. The innovation of practice teaching system could deepen the reform of higher pharmaceutical education and cultivate innovative talents, for the sake of meet the requirements of pharmaceutical education development and the need of modernization construction.

\section{DISCUSSION}

Along with the speeding up of globalization process, the higher education is becoming more and more open, meanwhile, it also faces fierce challenge domestic and overseas. The philosophy of striving for the survival with quality, continuous improvement of TQM and continuous promotion of quality will be accepted by more and more universities. Thus, it is necessary to boost the TQM step by step with a healthy system according to the characteristics of pharmaceutical education. It will play an important role in improving the quality of pharmaceutical education, by the achievement of increasing and qualified students for the development of medicine industry.

\section{CONCLUSION}

The report focuses on some problems encountering in higher pharmaceutical education in China, such as unevenness of school-running level, lack of students innovation and deficiency of teaching effect, in its rapid development. The reasons are explained by the analyses 
of teaching mode and enrollment scale in China's university. Total quality management (TQM), as a novel teaching concept, is suggested to integrate itself into higher pharmaceutical education via the following aspects. Firstly, the educators should take pharmaceutical moral as one of the important contents and infiltrate it in all teaching activities so as to realize the cultivation of professional ethics. Secondly, in order to improve course quality, it is necessary to implement curriculum reform by broadening curriculum caliber, optimizing curriculum system and removing regional segmentation in professional courses. Thirdly, practice teaching should be actively adopted to combine with higher pharmaceutical education due to it being a discipline depending largely on the practice. It is necessary to boost the TQM step by step with a healthy system, which will play an important role in improving the quality of pharmaceutical education. Though implementing TQM in higher pharmaceutical education faces various opportunity and challenge, the philosophy of TQM will be gradually accepted by more and more universities.

\section{ACKNOWLEDGEMENT}

We deeply appreciated Dr. Yanfeng Wang and Prof. Ye $\mathrm{Li}$ in Shenyang Pharmaceutical University, for the help of providing reference materials in this paper. This work was also supported by Shandong Provincial Development Project of Science and Technology (No. 2014GGX102037) and The National College Students' Innovative Entrepreneurial Training Plan (No. 201410448012).

\section{SUMMARY}

- The reasons for challenges to Chinese higher pharmaceutical education, are explained through the analyses of teaching mode and enrollment scale in China's university.

- TOM is proposed to integrate into higher pharmaceutical education.

- To implement TQM, suggestions are given on the aspects of professional ethics, course quality and practical teaching.

- It is necessary to boost TOM step by step with a healthy system, which will play an important role in improving the quality of pharmaceutical education.

\section{About Authors}

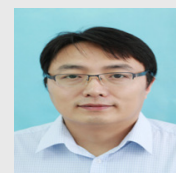

Xiangling Gu: Dr. Xiangling Gu is an associate professor at Dezhou University He received his Ph.D. from College of Chemisty and Chemical Engineering, Shandong University in 2010. Dr. Gu is one of the key members in Shandong Provincial Engineering Laboratory of Novel Pharmaceutical Excipients, Sustained and Controlled Release Preparations. Also, he serves as the member of Chinese Chemical Society. He specializes in research on higher pharmaceutical education and preparation of biomedical polymer.

\section{REFERENCES}

1. Wang Y, Li Y, Luo X, Liu Y. New thought on quality management in higher pharmaceutical education in China. Pharm Edu. 2006; 22(1): 4-6.

2. Williams G. Total quality management in higher education: panacea or placebo. Higher Edu.1993; 25(3): 229-37.

3. Sitkin SB, Sutcliffe KM, Schroeder RG. Distinguishing control from learning in total quality management: a contingency perspective. Academy of Management Review 1994; 19(3): 537-64.

4. Holdford D, Reinders TP. Development of an instrument to assess student perceptions of the quality of pharmaceutical education. American Journal of Pharmaceu Edu. 2001; 65(2): 125-31.

5. José Tarí J. Components of successful total quality management. The TQM magazine 2005; 17(2): 182-94.

6. Friedli T, Goetzfried M, Basu P. Analysis of the implementation of total productive maintenance, total quality management, and just-in-time in pharmaceutical manufacturing. Journal of Pharmaceutical Innovation 2010; 5(4): 181-92.

7. Hung YC, Huang SM, Lin QP, Tsai ML. Critical factors in adopting a knowledge management system for the pharmaceutical industry. J. Industrial Management and Data Systems 2005; 105(2): 164-83.

8. Usman Awan M, Raouf A, Ahmad N, Sparks L. Total quality management in developing countries: A case of pharmaceutical wholesale distribution in
Pakistan. International Journal of Pharmaceutical and Healthcare Marketing 2009; 3(4): 363-80.

9. Lawrence $X Y$. Pharmaceutical quality by design: product and process development, understanding, and control. Pharmaceutical Research 2008; 25(4): 781-91.

10. Kanji GK, Asher M. 100 methods for total quality management. Sage; 1996.

11. Chen HK, Chen HY, Wu HH, Lin WT. TQM implementation in a healthcare and pharmaceutical logistics organization: the case of Zuellig Pharma in Taiwan. Total Quality Management and Business Excellence 2004; 15(9-10): 1171-8.

12. Kezar AJ. Obtaining integrity? Reviewing and examining the charter between higher education and society. The Review of Higher Education 2004; 27(4): 429-59.

13. Wilson PF. Root cause analysis: A tool for total quality management. ASQ Quality Press; 1993

14. Van Mil JWF, Schulz M, Tromp TFJD. Pharmaceutical care, European developments in concepts, implementation, teaching, and research: a review. Pharmacy World and Science 2004; 26(6): 303-11.

15. Wu H, Khan MA, Hussain AS. Process control perspective for process analytical technology: integration of chemical engineering practice into semiconductor and pharmaceutical industries. Chemical Engineering Communications 2007; 194(6): 760-79.

16. Head S. The grim threat to British universities. The New York Review of Books; 2011. 